\title{
Responses of the Photosynthetic Electron Transport Reactions Stimulate the Oxidation of the Reaction Center Chlorophyll of Photosystem I, P700, under Drought and High Temperatures in Rice
}

\author{
Shinya Wada ${ }^{1,2}$, Daisuke Takagi ${ }^{2,3}{ }^{\circ}$, Chikahiro Miyake $^{2}$, Amane Makino ${ }^{3}$ and \\ Yuji Suzuki ${ }^{1, *}$ (i) \\ 1 Faculty of Agriculture, Iwate University, 3-18-8 Ueda, Morioka, Iwate 020-8550, Japan; \\ swada@penguin.kobe-u.ac.jp \\ 2 Graduate School of Agricultural Science, Kobe University, 1-1 Rokkodai, Nada-ku, Kobe 657-8501, Japan; \\ d.takagi@tohoku.ac.jp (D.T.); cmiyake@hawk.kobe-u.ac.jp (C.M.) \\ 3 Graduate School of Agricultural Science, Tohoku University, Aramaki-Aoba 468-1, Aoba-ku, \\ Sendai 980-8572, Japan; amanemakino@tohoku.ac.jp \\ * Correspondence: ysuzuki@iwate-u.ac.jp; Tel.: +81-19-621-6153
}

Received: 15 April 2019; Accepted: 24 April 2019; Published: 26 April 2019

\begin{abstract}
It is of interest how photosynthetic electron transport (PET) reactions respond to excess light energy caused by the combination of drought stress and high temperatures. Since such information is scarcely available for photosystem I (PSI), this question was explored in rice (Oryza sativa L.) plants subjected to drought stress, using culture solutions that contain poly(ethylene glycol) at different concentrations under two day/night temperature regimes. At $27 / 22{ }^{\circ} \mathrm{C}$ (day/night), drought stress led to the oxidation of the reaction center of the chlorophyll of PSI (P700), and also led to decreases in the quantum efficiencies of photosystem II (PSII) and PSI, and a reduction of the primary quinone electron acceptor of PSI. Such drought stress responses were wholly stimulated at $35 / 30^{\circ} \mathrm{C}$. These parameters were strongly correlated with each other and were minimally affected by temperature. These results indicate that the drought stress responses of the respective PET reactions are closely associated with each other in the oxidization of P700 and that such responses are stimulated at high temperatures. The underlying mechanisms of these phenomena were discussed. While P700 oxidation is thought to suppress reactive oxygen species (ROS) production, PSI photoinhibition was observed under severe stress conditions, implying that P700 oxidation is not sufficient for the protection of PSI under drought stress.
\end{abstract}

Keywords: drought stress; high temperature; excess light stress; photochemistry of photosystem II and I; rice

\section{Introduction}

Drought is one of the most serious abiotic stresses experienced by plants and is often accompanied by high temperatures. How the photosynthetic machinery responds to these stress conditions is of interest, as such information would be important for understanding and improving the stress tolerance of plants. Drought stress can lead to the generation of reactive oxygen species (ROS), which impair photosynthetic machinery. Stomatal closure in response to drought stress prevents water loss via transpiration but yields excess light energy, as decreases in $\mathrm{CO}_{2}$ availability within the leaves lead to decreases in energy consumption by the Calvin-Benson cycle [1]. Excess light energy can over-reduce the photosynthetic electron transport (PET) chain and lead to the generation of ROS [2,3]. Photosystem 
II and I (PSII and PSI, respectively) are known to be the generation sites of ROS [4-6]. Excess photons in PSII can generate triplet chlorophyll, with the subsequent formation of highly reactive singlet oxygen. It has been suggested that the over-reduction of the reaction center chlorophyll of PSI (P700) leads to the generation of ROS such as superoxide anions, hydroxyl radicals, and singlet oxygens (see [7], and the literature cited). The combination of drought stress and high temperatures can lead to the over-accumulation of ROS [8]. PSII photoinhibition is repaired efficiently in a short period of time $[9,10]$. In contrast, PSI photoinhibition, which does not occur frequently, requires a long period of recovery and severely affects photosynthesis and plant growth [11,12]. Therefore, we are interested primarily in the drought responses of the PSI photochemistry under high temperatures.

PSI is thought to be protected from excess light stress via the oxidation of P700, as indicated by increases in the quantum yield of the donor side limitation of PSI [Y(ND)] (see $[13,14])$. When P700 was in a more oxidized state under high irradiance, PSI was more tolerant to stress from strong excess light imposed by the repetitive illumination of a saturated pulse-light [13]. The photosynthetic processes, upstream and downstream of PSI, are thought to contribute to P700 oxidation. In the former case, P700 oxidation is promoted by decreasing electron flow to PSI. For example, excess light energy is dissipated as heat at PSII in a light-induced manner, namely, by non-photochemical quenching (NPQ) and a non-light-induced quenching process [5,15-17]. It has been suggested that NPQ contributes to the limitation of the downstream electron flow in the oxidation of P700 [18-23]. Electron flow is also limited at the cytochrome $b_{6} / f$ complex $[23,24]$. Luminal acidification is thought to play a regulatory role in NPQ induction and in limiting the electron flow at the cytochrome $b_{6} / f$ complex. It has also been suggested that the over-reduction of the plastoquinone pool suppresses the $\mathrm{Q}$ cycle and electron flow at the cytochrome $b_{6} / f$ complex in cyanobacteria, namely, the reduction-induced suppression of electron flow (RISE) $[25,26]$. The downstream processes of PSI, including photorespiration [27-29] and the reduction of $\mathrm{O}_{2}$ to $\mathrm{H}_{2} \mathrm{O}$ by flavodiiron proteins [30-33], are also thought to contribute to P700 oxidation.

When plants underwent drought stress, P700 oxidation was reported to be enhanced concomitantly with decreases in the quantum efficiency of PSII [Y(II)], which in turn were accompanied by increases in NPQ, a reduction of the plastoquinone pool, and decreases in the quantum efficiency of PSI $[Y(I)][1,18,20-22,34-36]$. These results suggest that the PET reactions, upstream of PSI, cooperatively respond to drought stress in order to protect P700 from over-reduction. It is also suggested that electron flow toward PSI is limited because of decreases in the amount of cytochrome $b_{6} / f$ complex [35]. High air temperatures were reported to stimulate the drought stress responses of PSII, triggering decreases in the maximal quantum efficiency of PSII $\left(F_{\mathrm{v}} / F_{\mathrm{m}}\right)$ and increases in NPQ [8,37-41].

However, it is still not clear whether (or how) PSI responds to the combination of drought and high temperatures, although this constitutes basic, important information on the protective mechanism of PSI. In order to explore this question, we determined the changes in the photochemistry of PSII and PSI and the rate of $\mathrm{CO}_{2}$ assimilation $(A)$ in the leaves of drought-stressed rice (Oryza sativa L.) plants under normal and high air temperature conditions. How responses of the PET reactions under drought stress were regulated was discussed in connection with the relationships between the measured parameters and the amount of cytochrome $f$ subunit of the cytochrome $b_{6} / f$ complex. In addition, the responses of the redox-state of P700 were compared with the maximal activity of PSI to assess the contribution of P700 oxidation to the protection of PSI from photoinhibition under drought stress.

\section{Results}

\subsection{Effects of Drought Stress at Different Temperatures on the Relative Water Contents of Leaves and A}

Drought stress treatments were carried out, following the methods described in Zhou et al. [34], with some slight modifications. Plants were treated with a culture solution containing poly(ethylene glycol) (PEG) at different concentrations for two days. A growth chamber was used to maintain consistent air temperatures and irradiance during the drought stress treatments. The conditions were 
a day/night temperature of $27 / 22{ }^{\circ} \mathrm{C}$ (normal temperature) or $35 / 30{ }^{\circ} \mathrm{C}$ (high temperature) and an irradiance of $450 \mu \mathrm{mol}$ photon $\mathrm{m}^{-2} \mathrm{~s}^{-1}$. Drought stress treatments induced the wilting of the leaves on the first day of treatment. Wilting was enhanced as [PEG] in the culture solutions increased at 27/22 ${ }^{\circ} \mathrm{C}$, and it tended to be further enhanced at $35 / 30{ }^{\circ} \mathrm{C}$. The extent of this symptom remained mostly unchanged during the treatments. The relative water content of the leaves after stress treatments decreased as [PEG] increased under both temperature conditions (Figure 1). The values recorded at $27 / 22^{\circ} \mathrm{C}$ were comparable with those previously reported [34]. Decreases in the relative water content were not stimulated at $35 / 30^{\circ} \mathrm{C}$, as had been previously observed in soil culture experiments with rice [42]. These results show that the leaf water status was negatively affected by the drought stress treatments in the present study.

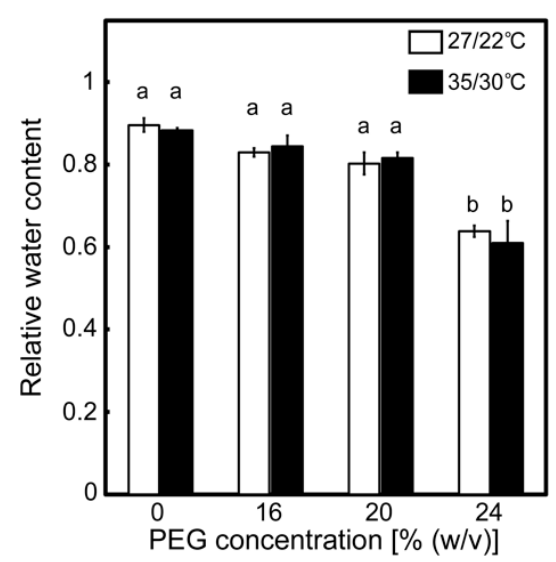

Figure 1. Relative water content of leaves after the drought stress treatment under two different temperature conditions in rice. Approximately 60 days after germination, hydroponically grown plants were drought-stressed using culture solutions containing PEG at $0,16,20$, and $24 \%(w / v)$ for two days under an irradiance of $450 \mu \mathrm{mol}$ photon $\mathrm{m}^{-2} \mathrm{~s}^{-1}$ and day/night temperature regimes of $27 / 22{ }^{\circ} \mathrm{C}$ and $35 / 30^{\circ} \mathrm{C}$. On the day following the stress treatment, the uppermost fully expanded leaves were collected for analysis. White and black bars denote plants stressed under the $27 / 22{ }^{\circ} \mathrm{C}$ and $35 / 30{ }^{\circ} \mathrm{C}$ conditions, respectively. Data are presented as means \pm SE ( $n=3$ to 5$)$. Statistical analysis was carried out by ANOVA, followed by Turkey-Kramer's test. Columns with the same letter were not significantly different $(p<0.05)$.

Photosynthetic parameters were measured at the end of the drought stress treatments under the conditions of light saturation and temperatures during drought stress treatments to assess the maximal photosynthetic activity under each stress condition. When gas-exchange parameters were examined, $A$ gradually decreased as the $[\mathrm{PEG}]$ in the culture solutions increased at $27 / 22^{\circ} \mathrm{C}$ (Figure 2a), whereas the decrease in $A$ was accompanied by decreases in stomatal conductance $\left(g_{\mathrm{s}}\right)$ (Figure 2b) [1]. At $35 / 30{ }^{\circ} \mathrm{C}, A$ and $g_{s}$ of the PEG-untreated control plants tended to be higher than those at $27 / 22{ }^{\circ} \mathrm{C}$ (Figure 2a,b). Decreases in $A$ and $g_{\mathrm{s}}$ were stimulated under high-temperature conditions, as previously observed $[40,41,43,44]$. However, air temperature had a minimal effect on the relative water content (Figure 1). These results mean that the Calvin-Benson cycle was inhibited by the stomatal closure caused by drought stress treatments and that the effects were stronger under high-temperature conditions.

\subsection{Responses of the PET Reactions}

The effects of drought stress at different temperatures on the maximum quantum efficiency of PSII photochemistry $\left(F_{\mathrm{v}} / F_{\mathrm{m}}\right)$ and the maximal P700 signal $\left(P_{\mathrm{m}}\right)$ were determined as indices for the photoinhibition of PSII and PSI, respectively (Figure 3). The values of $F_{\mathrm{v}} / F_{\mathrm{m}}$ were around 0.8 in the control plants and the $16 \%$ PEG-treated plants at $27 / 22{ }^{\circ} \mathrm{C}$. There was no statistically significant difference in the values of $F_{\mathrm{v}} / F_{\mathrm{m}}$ between the control plants and the PEG-treated plants, although the values of $F_{\mathrm{v}} / F_{\mathrm{m}}$ tended to marginally decrease in the $20 \%$ and $24 \%$ PEG-treated plants (Figure 3a). 
The values of $F_{\mathrm{v}} / F_{\mathrm{m}}$ were also around 0.8 in the control plants at $35 / 30{ }^{\circ} \mathrm{C}$, and they tended to marginally decrease in the $16 \%$ and $20 \%$ PEG-treated plants and drastically decreased to 0.490 in the $24 \%$ PEG-treated plants. These results show that considerable PSII photoinhibition occurred only when plants were subjected to severe drought stress at high temperatures. The values of $P_{\mathrm{m}}$ were around 2.9 in the control plants and the $16 \%$ and $20 \%$ PEG-treated plants at $27 / 22{ }^{\circ} \mathrm{C}$ but significantly decreased to 2.28 in the $24 \%$ PEG-treated plants (Figure 3b). Decreases in $P_{\mathrm{m}}$ were reported to be greater than those in $F_{\mathrm{v}} / F_{\mathrm{m}}$ when some tropical evergreen tree species were exposed to a prolonged drought [36], meaning that PSI is more susceptible to drought stress. Similar trends were observed in rice. The values of $P_{\mathrm{m}}$ were around 2.5 in the control plants and the $16 \%$ and 20\% PEG-treated plants at $35 / 30{ }^{\circ} \mathrm{C}$ but were drastically decreased to 0.75 in the $24 \%$ PEG-treated plants, showing that drought-induced PSI photoinhibition was enhanced at high temperatures.

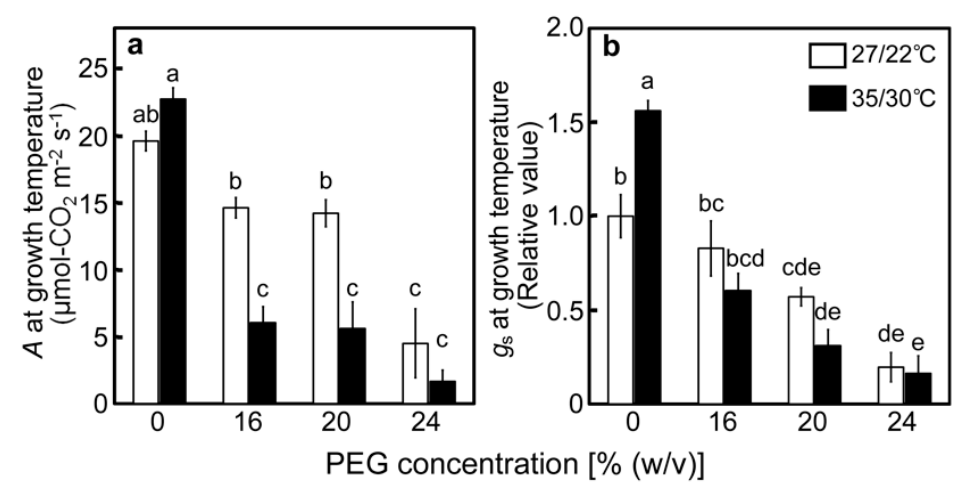

Figure 2. Rate of $\mathrm{CO}_{2}$ assimilation $(A)(\mathbf{a})$ and stomatal conductance $\left(g_{\mathrm{s}}\right)$ (b) after drought stress treatment under two different temperature conditions in rice. Approximately 60 days after germination, hydroponically grown plants were drought-stressed using culture solutions containing PEG at 0, 16, 20, $24 \%(w / v)$ for two days under an irradiance of $450 \mu \mathrm{mol}$ photon $\mathrm{m}^{-2} \mathrm{~s}^{-1}$ and day/night air-temperatures of $27 / 22{ }^{\circ} \mathrm{C}$ or $35 / 30{ }^{\circ} \mathrm{C}$, followed by measurements of $A$ and $g_{\mathrm{s}}$. Measurements were made under conditions of an actinic light intensity of $1250 \mu \mathrm{mol}$ photon $\mathrm{m}^{-2} \mathrm{~s}^{-1},\left[\mathrm{CO}_{2}\right]$ of $40 \mathrm{~Pa}$, leaf temperature of $27^{\circ} \mathrm{C}$ (white bar) or $35^{\circ} \mathrm{C}$ (black bar), which corresponded to the daytime air temperature during stress treatment, and relative humidity of $60-70 \%$. Data are presented as means \pm SE $(n=3$ to 5$)$. Statistical analysis was carried out by ANOVA, followed by Turkey-Kramer's test. Columns with the same letter were not significantly different $(p<0.05)$.

Changes in the photochemistry of PSII were examined in response to drought stress at different temperatures. The value of Y(II) in the control plants at $27 / 22{ }^{\circ} \mathrm{C}$ was 0.153 and tended to decrease as [PEG] in the culture solutions increased (Figure 4a). The quantum yield values of NPQ [Y(NPQ)] and the non-regulated and non-photochemical energy dissipation $[\mathrm{Y}(\mathrm{NO})]$ in the control plants were 0.646 and 0.201 , respectively (Figure $4 \mathrm{~b}, \mathrm{c})$. As decreases in $Y(\mathrm{II})$, caused by the PEG treatments, were accompanied by increases in both $Y(N P Q)$ and $Y(N O)$, changes in $Y(N P Q)$ and $Y(N O)$ were marginal. The value of $\mathrm{Y}$ (II) in the control plants at $35 / 30{ }^{\circ} \mathrm{C}$ was 0.203 , which is higher than that observed at $27 / 22{ }^{\circ} \mathrm{C}$ (Figure $4 \mathrm{a}$ ). The values of Y(II) greatly decreased in the PEG-treated plants at $35 / 30{ }^{\circ} \mathrm{C}$ and were lower than those in the PEG-treated plants at $27 / 22^{\circ} \mathrm{C}$. The values of $\mathrm{Y}(\mathrm{NPQ})$ and $\mathrm{Y}(\mathrm{NO})$ in the control plants were comparable to those at $27 / 22^{\circ} \mathrm{C}$ (Figure $4 \mathrm{~b}, \mathrm{c}$ ). Decreases in $\mathrm{Y}$ (II) were accompanied by slight increases in Y(NPQ) in the 16\% and 20\% PEG-treated plants. In contrast, in the $24 \%$ PEG-treated plants, where decreases in $F_{\mathrm{v}} / F_{\mathrm{m}}$ were observed (Figure $\left.3 \mathrm{a}\right), \mathrm{Y}(\mathrm{NO})$ showed a two-fold increase, whereas $\mathrm{Y}(\mathrm{NPQ})$ remained at the control level. The redox-state of the primary quinone electron acceptor of PSII $\left(Q_{A}\right)$ was determined by the value of $1-q_{L}$ (Figure $4 d$ ), which stands for the fraction of PS II centers in closed states, according to the definition of Kramer et al. [16]. The 1- $q_{L}$ is also thought to reflect the redox-state of the plastoquinone pool [45]. The values of $1-\mathrm{q}_{\mathrm{L}}$ in the control plants were 0.807 and 0.751 at $27 / 22{ }^{\circ} \mathrm{C}$ and $35 / 30^{\circ} \mathrm{C}$, respectively, and tended to increase as [PEG] in the culture solutions increased. The values of $1-q_{L}$ were greater at $35 / 30{ }^{\circ} \mathrm{C}$ under all [PEG] conditions. 

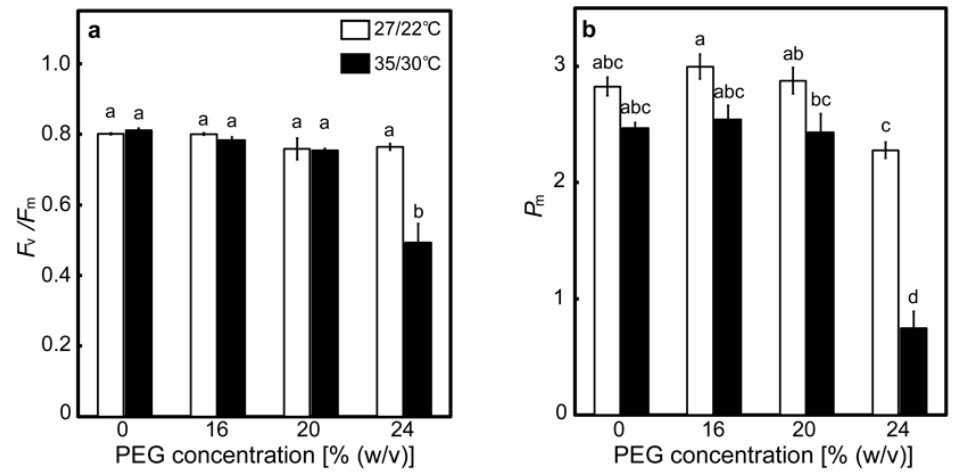

Figure 3. The maximum quantum efficiency of PSII photochemistry $\left(F_{\mathrm{v}} / F_{\mathrm{m}}\right)(\mathbf{a})$ and the maximal P700 signal $\left(P_{\mathrm{m}}\right)(\mathbf{b})$ after drought stress treatment under two different temperature conditions in rice. Approximately 60 days after germination, hydroponically grown plants were drought-stressed using culture solutions containing PEG at $0,16,20,24 \%(w / v)$ for two days under an irradiance of $450 \mu \mathrm{mol}$ photon $\mathrm{m}^{-2} \mathrm{~s}^{-1}$ and day/night air-temperatures of $27 / 22{ }^{\circ} \mathrm{C}$ or $35 / 30{ }^{\circ} \mathrm{C}$. Leaves were dark-adapted for more than $30 \mathrm{~min}$, followed by the measurements of $F_{\mathrm{v}} / F_{\mathrm{m}}$ and $P_{\mathrm{m}}$ under conditions of $\left[\mathrm{CO}_{2}\right]$ of $40 \mathrm{~Pa}$, leaf temperature of $27^{\circ} \mathrm{C}$ (white bar) or $35^{\circ} \mathrm{C}$ (black bar), which corresponded to the daytime air temperature during the stress treatment, and relative humidity of $60-70 \%$, without the illumination of actinic light. Data are presented as means \pm SE $(n=3$ to 5$)$. Statistical analysis was carried out by ANOVA, followed by Turkey-Kramer's test. Columns with the same letter were not significantly different $(p<0.05)$.
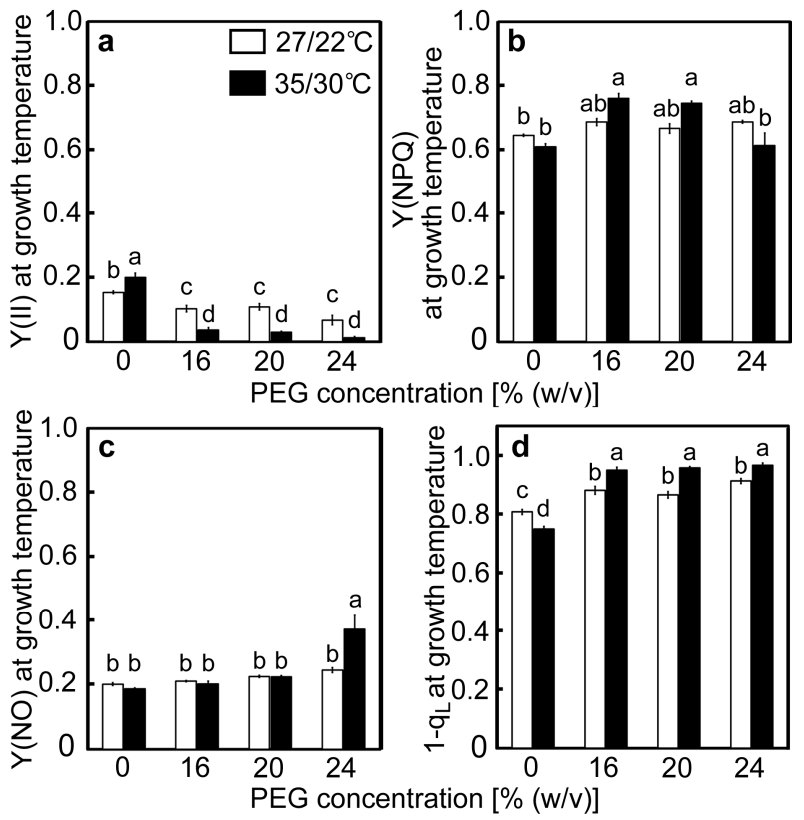

Figure 4. Chlorophyll fluorescence parameters after drought stress treatment under two different temperature conditions in rice. Approximately 60 days after germination, hydroponically grown plants were drought-stressed using culture solutions containing PEG at $0,16,20,24 \%(w / v)$ for two days under an irradiance of $450 \mu \mathrm{mol}$ photon $\mathrm{m}^{-2} \mathrm{~s}^{-1}$ and day/night air temperatures of $27 / 22{ }^{\circ} \mathrm{C}$ or $35 / 30{ }^{\circ} \mathrm{C}$. After the measurements of $F_{\mathrm{v}} / F_{\mathrm{m}}$ and $P_{\mathrm{m}}$, chlorophyll fluorescence parameters were measured. Panels (a), (b), (c), and (d) show the results for $\mathrm{Y}(\mathrm{II}), \mathrm{Y}(\mathrm{NPQ}), \mathrm{Y}(\mathrm{NO})$, and $1-\mathrm{q}_{\mathrm{L}}$, respectively. Measurements were made under conditions of an actinic light intensity of $1250 \mu \mathrm{mol}$ photon $\mathrm{m}^{-2} \mathrm{~s}^{-1}$, $\left[\mathrm{CO}_{2}\right]$ of $40 \mathrm{~Pa}$, leaf temperature of $27^{\circ} \mathrm{C}$ (white bar) or $35^{\circ} \mathrm{C}$ (black bar), which corresponded to the daytime air temperature during stress treatment, and relative humidity of $60-70 \%$. Data are presented as means \pm SE $(n=3$ to 5$)$. Statistical analysis was carried out by ANOVA, followed by Turkey-Kramer's test. Columns with the same letter were not significantly different $(p<0.05)$. 
Changes in the redox state of P700 were examined concurrently with the photochemistry changes of PSII. The value of $\mathrm{Y}(\mathrm{I})$ in the control plants at $27 / 22^{\circ} \mathrm{C}$ was 0.286 and tended to decrease as [PEG] in the culture solutions increased (Figure 5a). The values of $Y(N D)$ and the quantum yield of the acceptor side limitation of PSI [Y(NA)], which stand for the rate of P700 excitation, were 0.543 and 0.172 , respectively, in the control plants (Figure $5 b, c)$. Y(ND) increased as [PEG] in the culture solutions increased, whereas $\mathrm{Y}(\mathrm{NA})$ was unaffected by the PEG treatments. At $35 / 30^{\circ} \mathrm{C}$, the value of $\mathrm{Y}(\mathrm{I})$ in the control plants was 0.325 , which was higher than that observed at $27 / 22^{\circ} \mathrm{C}$ (Figure 5a). The values greatly decreased in the PEG-treated plants and were lower than those in the PEG-treated plants at $27 / 22{ }^{\circ} \mathrm{C}$. The values of $\mathrm{Y}(\mathrm{ND})$ and $\mathrm{Y}(\mathrm{NA})$ in the control plants were 0.444 and 0.193 , respectively (Figure $5 b, c)$. Decreases in $Y(I)$, caused by the PEG treatments, were accompanied by increases in $Y(N D)$, whereas $Y(N A)$ was unaffected. The decreases observed in $Y(I)$, caused by the PEG treatments, primarily reflected the increases in $\mathrm{Y}(\mathrm{ND})$ at both temperatures.
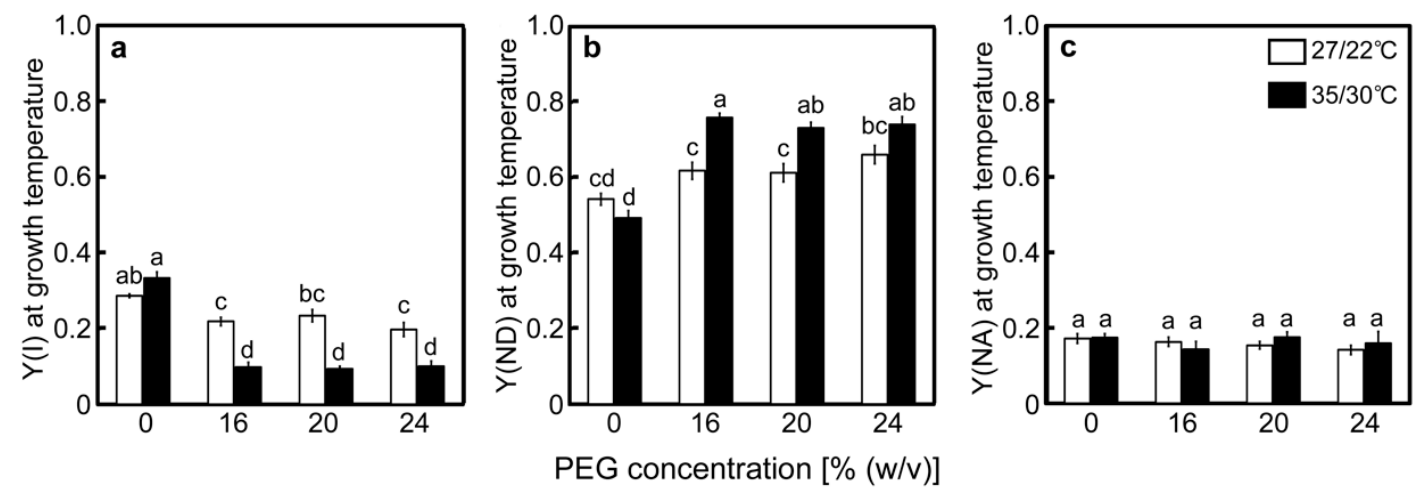

Figure 5. Redox state of P700 after drought stress treatment under two different temperature conditions in rice. Approximately 60 days after germination, hydroponically grown plants were drought-stressed using culture solutions containing PEG at $0,16,20,24 \%(w / v)$ for two days under an irradiance of $450 \mu \mathrm{mol}$ photon $\mathrm{m}^{-2} \mathrm{~s}^{-1}$ and day/night air temperatures of $27 / 22{ }^{\circ} \mathrm{C}$ or $35 / 30{ }^{\circ} \mathrm{C}$. P700 absorption was measured simultaneously with chlorophyll fluorescence. Panels (a), (b), and (c) show the results for $\mathrm{Y}(\mathrm{I}), \mathrm{Y}(\mathrm{ND})$, and $\mathrm{Y}(\mathrm{NA})$, respectively. Measurements were made under conditions of an actinic light intensity of $1250 \mu \mathrm{mol}$ photon $\mathrm{m}^{-2} \mathrm{~s}^{-1}$, $\left[\mathrm{CO}_{2}\right]$ of $40 \mathrm{~Pa}$, leaf temperature of $27^{\circ} \mathrm{C}$ (white bar) or $35^{\circ} \mathrm{C}$ (black bar), which corresponded to the daytime air temperature during stress treatment, and relative humidity of $60-70 \%$. Data are presented as means \pm SE ( $n=3$ to 5$)$. Statistical analysis was carried out by ANOVA, followed by Turkey-Kramer's test. Columns with the same letter were not significantly different $(p<0.05)$.

\subsection{Relationships between the Photosynthetic Parameters}

The relationships between the photosynthetic parameters were investigated (Table S1). Strong correlations were observed between $A, \mathrm{Y}(\mathrm{II}), 1-\mathrm{q}_{\mathrm{L}}, \mathrm{Y}(\mathrm{I})$, and $\mathrm{Y}(\mathrm{ND})$. Those correlations are shown in Figure 6. Comparisons were made between $Y($ III $)$ and $A$, to examine the effects of decreases in $A$ on linear electron flow, and between $1-\mathrm{q}_{\mathrm{L}}$ and $\mathrm{Y}(\mathrm{II}), \mathrm{Y}(\mathrm{I})$ and $1-\mathrm{q}_{\mathrm{L}}$, and $\mathrm{Y}(\mathrm{ND})$ and $\mathrm{Y}(\mathrm{I})$, to examine the mutual relationships between the successive PET reactions. Y(II) was positively correlated with $A$ under both air temperature conditions (Figure 6a), although the relationship was affected slightly by temperature. Y(II) changed proportionally with $A$ at $35 / 30^{\circ} \mathrm{C}$, as the regression line passed near the origin, whereas the changes in $Y\left(\right.$ II) were smaller at $27 / 22^{\circ} \mathrm{C}$. Strong negative correlations were observed between $1-q_{L}$ and $Y(I I), Y(I)$ and $1-q_{L}$, and $Y(N D)$ and $Y(I)$ (Figure $6 b-d$ ). While there were statistically significant differences in the relationships between $1-q_{L}$ and $Y(I I)$, and $Y(I)$ and $1-q_{L}$, depending on the air temperatures, the differences in the slopes and intercepts were small (less than $10 \%)$. 

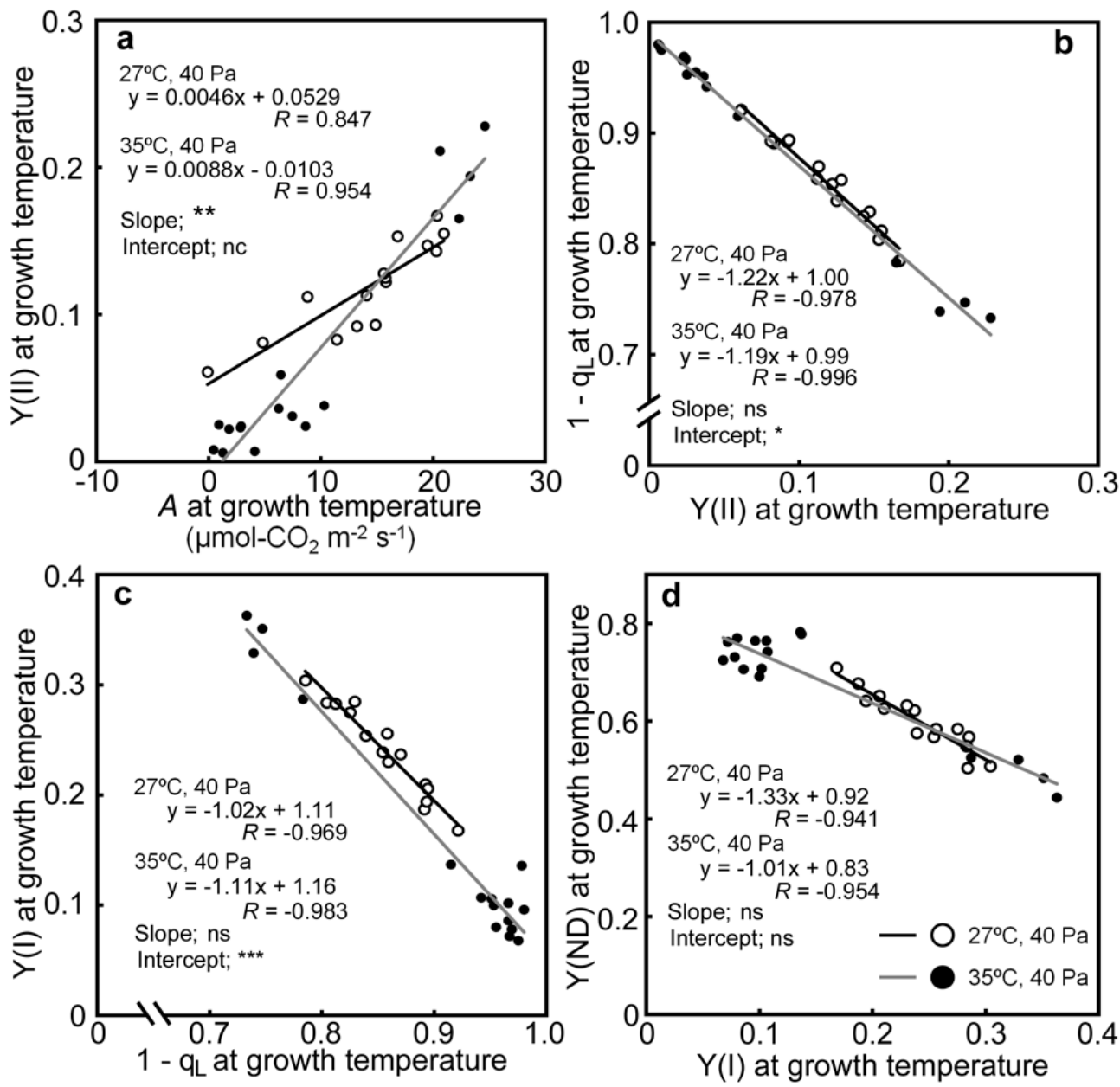

Figure 6. Relationship between $\mathrm{Y}(\mathrm{II})$ and $A(\mathbf{a}), 1-\mathrm{q}_{\mathrm{L}}$ and $\mathrm{Y}(\mathrm{I})$ and $\mathrm{Y}(\mathrm{II})(\mathbf{b}), \mathrm{Y}(\mathrm{I})$ and $1-\mathrm{q}_{\mathrm{L}}(\mathbf{c})$, and $\mathrm{Y}(\mathrm{ND})$ and $Y(I)(d)$. The data are taken from Figure 2, Figure 4, and Figure 5. Regression lines were made from a dataset, obtained at a given air temperature. White and black circles correspond to data obtained from drought-stressed plants at $27 / 22^{\circ} \mathrm{C}$ and $35 / 30{ }^{\circ} \mathrm{C}$, respectively. The results of statistical treatments between regression lines by ANCOVA were presented in each panel. The slopes of regression lines were tested first. When there were no significant differences, the intercepts of the regression lines were tested. ${ }^{*}, * *$, and ${ }^{* * *}$ denote statistically significant differences at $p<0.05,0.01$, and 0.001 , respectively. The ns and nc notations denote not significant and not calculated, respectively.

\subsection{Effects of Drought Stress on the Amount of Cytochrome $f$}

As it was suggested that decreases in the cytochrome $b_{6} / f$ content limit downstream electron flow and prevent the over-reduction of P700 under drought stress [35], one of its subunits (cytochrome $f$ ) was determined. The results of the detection of cytochrome $f$ by Western blotting, followed by SDS-PAGE, are shown in Figure S1. Relative amounts of cytochrome $f$ were shown on a leaf fresh weight basis, a leaf area basis, and a chlorophyll content basis (Figure 7a-c). The amount of cytochrome $f$ was relatively stable under stress conditions, with a maximum decrease of approximately $30 \%$ observed in the $20 \%$ PEG-treated plants at $27 / 22{ }^{\circ} \mathrm{C}$. Decreases in the amount of cytochrome $f$ were not stimulated at $35 / 30{ }^{\circ} \mathrm{C}$. 

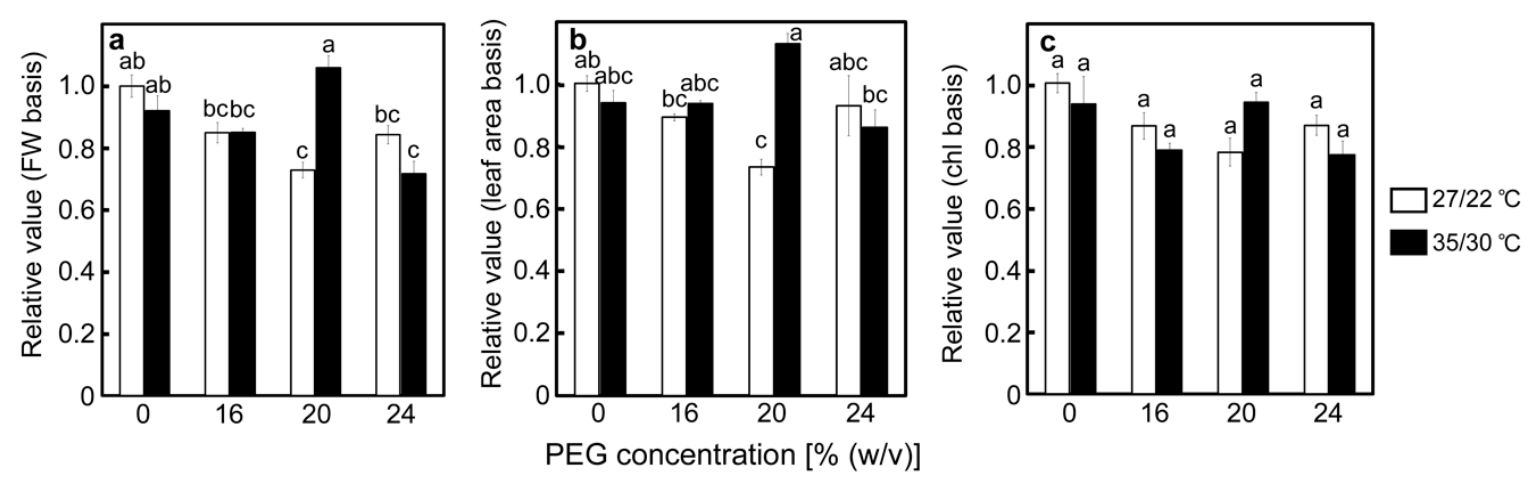

Figure 7. The relative amount of cytochrome $f$ after drought stress treatment on a leaf fresh weight basis (a), leaf area basis (b), and unit chlorophyll content basis (c) under two different temperature conditions in rice. Approximately 60 days after germination, hydroponically grown plants were drought-stressed using culture solutions containing PEG at $0,16,20,24 \%(w / v)$ for two days under an irradiance of 450 $\mu \mathrm{mol}$ photon $\mathrm{m}^{-2} \mathrm{~s}^{-1}$ and day/night air temperatures of $27 / 22^{\circ} \mathrm{C}$ or $35 / 30{ }^{\circ} \mathrm{C}$, followed by western blotting using polyclonal-monospecific antibodies against cytochrome $f$. Data of the PEG-untreated control plants were defined as 1 . Data are presented as means $\pm \operatorname{SE}(n=3)$. Statistical analysis was carried out by ANOVA, followed by Turkey-Kramer's test. Columns with the same letter were not significantly different $(p<0.05)$.

\section{Discussion}

\subsection{Drought Stress Responses of the PET Reaction that Leads to P700 Oxidization Are Stimulated under High Temperatures}

We tried to characterize drought stress responses of the PET reactions, focusing especially on the redox state of PSI at high temperatures in rice. At normal temperatures, it is the drought stress responses of the PET reactions are to limit the electron flow to PSI [1,18,20-22,34-36]. Our results at $27 / 22{ }^{\circ} \mathrm{C}$ were consistent with these previous reports. Decreases in $A$ and $g_{\mathrm{s}}$ under drought stress led to the limitation of the linear electron flow, as indicated by the decreases in Y(II) (Figures 2 and 4a). Subsequently, the reduction of $\mathrm{Q}_{\mathrm{A}}$, decrease in the electron flow at PSI, and oxidation of P700 occurred, as indicated by the increases in $1-\mathrm{q}_{\mathrm{L}}$, decreases in $\mathrm{Y}(\mathrm{I})$, and increases in $\mathrm{Y}(\mathrm{ND})$, respectively (Figures 4 and 5). In the present study, it was further found that these drought stress responses were wholly stimulated under the high-temperature conditions of $35 / 30{ }^{\circ} \mathrm{C}$ (Figures 4 and 5). Interestingly, these PET reaction parameters were strongly correlated with each other and were minimally affected by temperature during stress treatments (Table S1; Figure 5). These results indicated that the drought stress responses of the respective PET reactions were closely associated with each other in the oxidation of P700 and that such responses are stimulated at high temperatures.

The photoinhibition of PSI or PSII and PSI was observed in the 24\% PEG-treated plants at $27 / 22{ }^{\circ} \mathrm{C}$ or $35 / 30{ }^{\circ} \mathrm{C}$ (Figure 3). Whether this photoinhibition affected the drought stress response of the PET reactions is an issue. The strong correlations between the parameters of the PET reactions were observed, even in the presence of photoinhibition (Table S1; Figure 6), implying that the effects of the photoinhibition were small in the present experimental condition. The following previous observation might support this assumption. Decreases in $F_{\mathrm{v}} / F_{\mathrm{m}}$ led to decreases in $A$, but such effects became small under low $\left[\mathrm{CO}_{2}\right]$ conditions in Chenopodium album [46], implying that linear electron flow was not greatly affected by $F_{\mathrm{v}} / F_{\mathrm{m}}$ when $A$ was suppressed. Parameters, such as $\mathrm{Y}(\mathrm{II})$ and $A$, tended to be greatly affected by drought stress conditions, rather than by $F_{\mathrm{v}} / F_{\mathrm{m}}$, in tomato and citrus [38-40]. On the other hand, it has been reported that the specific photoinhibition of PSI affected other photosynthetic processes, including decreases in $\mathrm{Y}(\mathrm{II})$, the reduction of $\mathrm{Q}_{\mathrm{A}}$, and decreases in $A$ in wheat and Arabidopsis, when measured under normal or elevated $\left[\mathrm{CO}_{2}\right]$ conditions $[47,48]$. However, it is still unknown how these parameters respond when $A$ is severely suppressed. At least, $\mathrm{Y}(\mathrm{II})$ and $A$, 
measured under high irradiance, also seemed to be affected by drought stress conditions, rather than by $P_{\mathrm{m}}$, in some tropical tree species [36].

\subsection{Possible Mechanisms of the Drought Stress Responses of the PET Reactions at High Temperatures}

It is of interest how the drought stress response of the PET reactions was regulated at high temperatures. Luminal acidification would be one candidate for the regulatory factors, as it induces NPQ at PSII $[5,15,20]$ and slows down the oxidation of plastoquinol by the cytochrome $b_{6} / f$ complex $[23,24,49]$. Such regulations are thought to occur under drought stress at non-stressful temperatures [22,35]. A decrease in $\mathrm{q}_{\mathrm{L}}$ could reflect luminal acidification as these phenomena were simultaneously observed when the amounts of the chloroplastic ATP synthase were decreased in transgenic and transplastomic tobacco plants [23]. In the present study, the values of $1-\mathrm{q}_{\mathrm{L}}$ increased and were strongly correlated with other parameters of the PET reactions, irrespective of the temperature (Table S1; Figures 4d and 6). These results imply the regulation of the drought stress responses of the PET reactions by luminal acidification at high temperatures in rice. Increases in 1- $\mathrm{q}_{\mathrm{L}}$ are also thought to reflect a reduction of the plastoquinone pool [45], which was suggested to play a regulatory role in the PET reactions when photosynthesis was inhibited. In cyanobacteria, cultured under $\mathrm{CO}_{2}$-depleted conditions, an over-reduction of the plastoquinone pool was shown to inhibit the $\mathrm{Q}$ cycle at the cytochrome $b_{6} / f$ complex and limit the downstream electron flow, leading to P700 oxidation $[25,26]$. It might be reasonable to assume that the same regulatory mechanism operated under drought stress at high temperatures in rice, although it remains unclear whether this mechanism is operative in vascular plants. In addition, decreases in the amount of cytochrome $b_{6} / f$ complex have been suggested to limit the electron flow to PSI in response to drought stress at non-stressful temperatures. The amount of cytochrome $b_{6} / f$ complex, as well as the linear electron flow at PSII in drought-stressed wild watermelon plants, decreased to approximately $50 \%$ of the levels observed in non-stressed plants [35]. Such a substantial decrease in the cytochrome $f$ content was not observed in the present study (Figure S1 and Figure 7), and it is unlikely that such regulation occurred in rice, irrespective of the temperature. The difference between these studies may be attributed to different strategies for protecting PSI under drought stress conditions in different plant species.

It has also been suggested that P700 oxidation under drought stress is related to operation of the cyclic electron flow around PSI (CEF-PSI), leading to the formation of luminal acidification, induction of NPQ, and suppression of ROS production in PSII [18,50]. The rationale for the operation of CEF-PSI was the observation that $Y(I)$ was higher than $Y(I I)[18,20-22]$. Similar results were also observed in the present study (Figures $4 a$ and $5 a$ ). To assess whether CEF-PSI is operative under drought stress in more detail, the simultaneous monitoring of the redox state of P700, plastocyanin, and ferredoxin, as well as chlorophyll fluorescence [51,52], would be useful. Recently, Takagi and Miyake [53] used this system to determine the ratios of the linear electron flow rates to the ferredoxin oxidation rates as an index of the activity of ferredoxin-dependent CEF-PSI in Arabidopsis. It was found that the activity of ferredoxin-dependent CEF-PSI was minor under normal conditions. How this situation changes under drought stress needs to be studied.

While the changes in Y(II) were positively correlated with those in $A$ under drought stress, temperature affected this relationship. The decreases in $Y($ II) were relatively smaller than those in $A$ at $27 / 22{ }^{\circ} \mathrm{C}$ (Figures 2a, 4a and $6 \mathrm{a}$ ), agreeing with previous reports on drought stress at normal temperatures $[1,18,21,22]$. Such phenomena are related to the operation of photorespiration. While $A$ decreased because of drought stress, the rate of energy consumption by photorespiration was shown to increase [54-58], leading to the maintenance of $Y($ II), unlike $A$. On the other hand, the regression line between $\mathrm{Y}(\mathrm{II})$ and $A$ passed near the origin at $35 / 30{ }^{\circ} \mathrm{C}$ (Figure 6a), indicating that $\mathrm{Y}$ (II) was primarily dependent on $A$. One explanation might be the inhibition of photorespiration. Considerable decreases in $\mathrm{Y}$ (II) were also observed when $\mathrm{CO}_{2}$ assimilation and photorespiration were inhibited under the combination of low $\left[\mathrm{CO}_{2}\right]$ and low $\left[\mathrm{O}_{2}\right]$ conditions [28]. It is unlikely that PSI and PSII photoinhibition greatly affected the relationship between $\mathrm{Y}$ (II) and $A$, as mentioned before. It was reported that some 
photorespiratory enzymes were unaffected even under severe drought stress, whereas those of the Calvin-Benson cycle, such as NADP-dependent glyceraldehyde-3-phosphate dehydrogenase and fructose-1,6-bisphosphatase, decreased [54]. In the present study, it is possible that some unknown inhibition of the photorespiratory pathway occurred under the combination of drought stress and high temperatures. On the other hand, it is also possible that photorespiration operated similarly under drought stress at high temperatures. It has previously been observed that $\mathrm{Y}(\mathrm{NA})$ increased under $\mathrm{CO}_{2}$-limited conditions when the activity of $\mathrm{CO}_{2}$ assimilation/photorespiration was decreased by the antisense suppression of Rubisco content in rice [29]. Such changes in Y(NA) were not observed in the present study (Figure 5c). Further validation through biochemical assays will be necessary to assess this hypothesis concerning the inhibition of photorespiration.

\subsection{P700 Oxidation Is not Sufficient for the Protection of PSI from Photoinhibition under Drought Stress}

P700 oxidation is thought to contribute to the prevention of PSI photoinhibition via the suppression of ROS production at PSI $[13,14]$. While Y(ND) tended to increase as stress became strong (Figure $5 b$ ), PSI photoinhibition was observed in the 24\% PEG-treated plants at both temperatures (Figure 3b), meaning that P700 oxidation is not sufficient to fully prevent PSI photoinhibition under drought stress at high and normal temperatures. Previous reports have implied that ROS generation and oxidative damage is unavoidable in leaves. Even when P700 oxidation was stimulated in the presence of strong actinic light illumination, excess light stress, imposed by repetitive illumination of saturated pulse light, decreased $P_{\mathrm{m}}$ to some extent in some plant species, including rice [13,14,29]. While ROS generation can be greatly suppressed by P700 oxidation, ROS, unavoidably generated, might be harmful under drought stress. It has also been suggested that mechanisms, other than P700 oxidation, are involved in protection against ROS. For example, the tolerance of PSI to the repetitive illumination of saturated pulse light differed among angiosperms when it was imposed in the absence of actinic light illumination and P700 oxidation was not induced [14]. In addition, severe drought stress increased the rate of mitochondrial respiration to compensate for decreased ATP production in chloroplasts, leading to enhanced ROS production in mitochondria [59]. ROS accumulation in mitochondria can lead to programmed cell death [60]. Such mechanisms might have been affected by drought stress, leading to damage to the PSI. Further investigation is necessary to unveil the mechanisms of PSI photoinhibition under drought stress and its temperature dependence.

\section{Conclusions}

Drought stress decreased $A$ and $g_{s}$, triggering the oxidation of P700 via the responses of the PET reactions, such as decreases in $Y(\mathrm{II})$, the reduction of $\mathrm{Q}_{\mathrm{A}}$, and decreases in $\mathrm{Y}(\mathrm{I})$, in rice. Such responses were wholly stimulated under drought stress at high temperatures. Strong correlations between the PET reactions parameters indicate that drought stress responses of the PET reactions are closely associated with each other, irrespective of temperature, leading to the stimulation of the whole drought stress response at high temperatures. Luminal acidification and/or the reduction of the plastoquinone pool may be potential regulatory factors of the drought stress response of the PET reactions at high temperatures. It is also implied that the contribution of photorespiration to the consumption of excess light energy was decreased under drought stress at high temperatures due to its inhibition. P700 oxidation is expected to protect PSI from photoinhibition. However, although P700 oxidation was stimulated, PSI photoinhibition was observed under severe drought stress, meaning that P700 oxidation is not sufficient for the protection of PSI from photoinhibition under drought stress. The detailed mechanism of the drought stress responses at high temperatures remain unknown and require further study. Whether similar drought stress responses are observed at high temperatures in other plant species is also of interest and needs to be studied. 


\section{Materials and Methods}

\subsection{Plant Materials and Growth Conditions}

Rice (Oryza sativa L. 'Notohikari') plants were hydroponically grown in an air-conditioned greenhouse (S-153A, Koito Manufacturing Co. Ltd., Tokyo, Japan) under natural sunlight conditions. Light was supplemented from 0500 to 1900 by two LED lamp units (1000 W Hydroponic Growing Lighting LED Plant Light, Chonquing Hanfan Technology Co. Ltd., Chongqing, China) outputting $200 \mu \mathrm{mol}$ photon $\mathrm{m}^{-2} \mathrm{~s}^{-1}$ at plant height. Day/night temperatures were $27 / 22{ }^{\circ} \mathrm{C}$. After germination and culturing in tap water for 20 days, each seedling was transplanted to a $1.1 \mathrm{~L}$ plastic pot containing a nutrient solution, as previously described in [61]. The nutrient solution was renewed once a week. The strength of the nutrient solution was increased, depending on the plant growth. The uppermost fully expanded leaves were used for the experiments, from approximately 60 days after germination, when the 11th leaf on the main culm was almost fully expanded.

\subsection{Drought Stress Treatment}

Drought stress treatments were carried out, following the methods of Zhou et al. [34]. Approximately 60 days after germination, when the 11th leaf of the main culm was fully expanded, the plants were transferred to environmentally controlled growth chambers, operated with two different air-temperature conditions and fed nutrient solutions containing PEG at different concentrations for two days to induce drought stress. The growth chambers (NC-411HC, NK System, Osaka, Japan) were operated with an irradiance of $450 \mu \mathrm{mol}$ photon $\mathrm{m}^{-2} \mathrm{~s}^{-1}$, a $14 \mathrm{~h}$ photoperiod, and a day/night air-temperature of $27 / 22{ }^{\circ} \mathrm{C}$ and $35 / 30{ }^{\circ} \mathrm{C}$ for the normal and high-temperature conditions, respectively. PEG, with an average molecular weight of 6000 (PEG, Sigma-Aldrich, St. Louis, MO, USA), was used in all treatments. The concentrations of PEG used in the culture solutions were 16, 20, and $24 \%$ $(w / v)$. A nutrient solution without PEG was used as the control treatment. The day after the drought stress treatment, P700 absorbance and chlorophyll fluorescence parameters were measured, as described below.

\subsection{Measurements of the Relative Water Content of Leaves}

The relative water content of the leaves was determined after the stress treatment, following the methods of Zhou et al. [34]. Leaves were collected, immediately weighed ( $\left.\mathrm{FW}_{1}\right)$, immersed overnight in deionized water at $4{ }^{\circ} \mathrm{C}$, and weighed again $\left(\mathrm{FW}_{2}\right)$. The dry weight $(\mathrm{DW})$ of the leaves was measured, after being dried at $70{ }^{\circ} \mathrm{C}$ for at least 3 days. The relative water content was calculated as $\left(\mathrm{FW}_{1}-\mathrm{DW}\right) /\left(\mathrm{FW}_{2}-\mathrm{DW}\right)$.

\subsection{Measurements of Photosynthesis}

Chlorophyll fluorescence, P700 absorbance, and $A$ were simultaneously measured using a GFS-3000 and a DUAL-PAM-100 m conjunction system (Heinz Walz GmbH, Effeltrich, Germany). Plants were kept in the dark for at least $30 \mathrm{~min}$ prior to the measurements. Measurements were initiated at a $\left[\mathrm{CO}_{2}\right]$ of $40 \mathrm{~Pa}$. The leaf temperature was either $27^{\circ} \mathrm{C}$ or $35^{\circ} \mathrm{C}$, corresponding to the air temperature during stress treatment. The relative air humidity was 60 to $70 \%$. The minimal fluorescence in the dark-adapted state $\left(F_{\mathrm{o}}\right)$ was recorded after the illumination of a weak measuring light $(620 \mathrm{~nm})$ at a photon flux density of $0.05-0.1 \mu \mathrm{mol}$ photon $\mathrm{m}^{-2} \mathrm{~s}^{-1}$. A saturating pulse light $(300 \mathrm{~ms}, 10,000 \mu \mathrm{mol}$ photon $\left.\mathrm{m}^{-2} \mathrm{~s}^{-1}\right)$ was applied to determine the maximal fluorescence in the dark-adapted state $\left(F_{\mathrm{m}}\right)$. Leaves were equilibrated under actinic light illumination $\left(1250 \mu \mathrm{mol}\right.$ photon $\left.\mathrm{m}^{-2} \mathrm{~s}^{-1}\right)$. The maximal and minimal fluorescence in the light-adapted state $\left(F_{\mathrm{m}}{ }^{\prime}\right.$ and $\left.F_{\mathrm{o}}{ }^{\prime}\right)$ and steady-state chlorophyll fluorescence $\left(F_{\mathrm{s}}\right)$ were recorded after 20 to $30 \mathrm{~min}$ of exposure to the actinic light illumination. Prior to measuring $F_{\mathrm{m}}{ }^{\prime}$ and $F_{\mathrm{o}}{ }^{\prime}$, a saturating pulse light and far-red light $(720 \mathrm{~nm})$ were applied, respectively. Chlorophyll fluorescence parameters were calculated, following the methods of Kramer et al. [16] and Baker [62]. The maximal quantum yield of PSII and NPQ were calculated as $F_{\mathrm{v}} / F_{\mathrm{m}}$ and $\left(F_{\mathrm{m}}-F_{\mathrm{m}}{ }^{\prime}\right) / F_{\mathrm{m}}{ }^{\prime}$, 
respectively. The index for the reduction of the primary plastoquinone electron acceptor $\left(\mathrm{Q}_{\mathrm{A}}\right)\left(1-\mathrm{q}_{\mathrm{L}}\right)$ was calculated as $1-\left(F_{\mathrm{m}}{ }^{\prime}-F_{s}\right) /\left(F_{\mathrm{m}}{ }^{\prime}-F_{\mathrm{o}}{ }^{\prime}\right) \times\left(F_{\mathrm{o}}{ }^{\prime} / F_{s}\right)$. Y(II), $\mathrm{Y}(\mathrm{NO})$, and $\mathrm{Y}(\mathrm{NPQ})$ were calculated as $\left(F_{\mathrm{m}}{ }^{\prime}-F_{\mathrm{s}}\right) / F_{\mathrm{m}}{ }^{\prime}, 1 /\left[\mathrm{NPQ}+1+\mathrm{q}_{\mathrm{L}}\left(F_{\mathrm{m}} / F_{\mathrm{o}}-1\right)\right]$, and $1-\mathrm{Y}(\mathrm{II})-1 /\left[\mathrm{NPQ}+1+\mathrm{q}_{\mathrm{L}}\left(F_{\mathrm{m}} / F_{\mathrm{o}}-1\right)\right]$, respectively. Three complementary quantum yields were defined: $Y(I I)+Y(N O)+Y(N P Q)=1$. The redox change of P700 was assessed, according to Klughammer and Schreiber [63], as described in [64], simultaneously with the chlorophyll fluorescence measurements. The maximal P700 signal $\left(P_{\mathrm{m}}\right)$ was determined by the application of a saturated pulse light in the presence of far-red light $(720 \mathrm{~nm})$, while that of the oxidized P700 during actinic light illumination $\left(P_{\mathrm{m}}{ }^{\prime}\right)$ was determined by a saturated pulse-light application. The P700 signal during actinic light illumination $(P)$ was recorded just prior to the saturated pulse light application. $\mathrm{Y}(\mathrm{I}), \mathrm{Y}(\mathrm{NA})$, and $\mathrm{Y}(\mathrm{ND})$ were calculated as $\left(P_{\mathrm{m}}{ }^{\prime}-P\right) / P_{\mathrm{m}},\left(P_{\mathrm{m}}-P_{\mathrm{m}}{ }^{\prime}\right) / P_{\mathrm{m}}$, and $P / P_{\mathrm{m}}$, respectively. Three complementary quantum yields were defined: $Y(I)+Y(N A)+Y(N D)=1 . A$ and $g_{\mathrm{s}}$ were also simultaneously recorded. The values of $g_{\mathrm{s}}$ were presented as relative values, where the values of the PEG-untreated control plants at $27 / 22{ }^{\circ} \mathrm{C}$ were defined as 1 .

\subsection{Determination of Cytochrome $f$ Contents}

After the drought stress treatment, leaves equivalent to those used for the photosynthetic measurements were collected, frozen in $\mathrm{LN}_{2}$, and stored at $-80{ }^{\circ} \mathrm{C}$, after the leaf area and fresh weight were measured. Samples were homogenized with sodium-phosphate buffer, and the amount of chlorophyll was measured. Treatments with SDS were performed as described in [65] but used the leaf homogenate for SDS treatment, instead of the supernatant of the leaf homogenate. Western blotting was conducted as described in [66], with modifications. An aliquot of each SDS-treated sample, corresponding to a leaf fresh weight of $0.09 \mathrm{mg}$, were loaded onto a gel. Different volumes of SDS-treated samples, prepared from the PEG-untreated control plants at $27 / 22{ }^{\circ} \mathrm{C}$, corresponding to leaf fresh weights of $0.03,0.06,0.12$, and $0.18 \mathrm{mg}$, were loaded onto a gel to generate a calibration curve. Polyclonal-monospecific antibodies against cytochrome $f$ [67] were used for immunological detection. The signal intensity was normalized on a leaf area basis or a chlorophyll content basis.

\subsection{Statistical Treatment}

Three to five biological replicates were used. The data shown in Figures 1-4 were statistically analyzed using the Tukey-Kramer's HSD test with JMP11 (SAS Institute Japan, Tokyo, Japan). For the data shown in Figure 5, the Pearson correlation coefficients of the measured parameters and their $P$-values were calculated using Microsoft Excel. Statistically significant differences between the regression lines in Figure 5 were tested using an analysis of covariance (ANCOVA). The slopes of the regression lines were tested first, and the intercepts were tested if no significant differences were determined. Analyses were carried out using R [68].

Supplementary Materials: Supplementary materials can be found at http://www.mdpi.com/1422-0067/20/9/2068/s1.

Author Contributions: Y.S. conceived and designed the experiments. S.W. performed the experiments. Y.S., S.W., D.T., C.M., and A.M. analyzed the data and wrote the manuscript.

Funding: This study was supported by the Core Research for Environmental Science and Technology (Scientific Research Grant No. AL65D21010 to C.M.) and Grants-in-Aid for Scientific Research from the Japan Society for the Promotion of Science (No. 18H02111 to Y.S. and No. 16H06379 to A.M.).

Acknowledgments: We thank Mr. Mao Suganami (Tohoku University) for his kind technical assistance.

Conflicts of Interest: The authors declare no conflict of interest. 


\section{Abbreviations}

A

the rate of $\mathrm{CO}_{2}$ assimilation

$\begin{array}{ll}\text { CEF-PSI } & \text { cyclic electron flow around photosystem I } \\ \mathrm{gH}^{+} & \text {the conductance of } \mathrm{H}^{+} \text {across the thylakoid membranes } \\ g_{\mathrm{s}} & \text { stomatal conductance } \\ \mathrm{NPQ} & \text { non-photochemical quenching } \\ \text { P700 } & \text { the reaction center chlorophyll of photosystem I } \\ \text { PEG } & \text { poly (ethylene glycol) } \\ \text { PET } & \text { photosynthetic electron transport } \\ \text { PSII } & \text { photosystem II } \\ \text { PSI } & \text { photosystem I } \\ \text { QA } & \text { the primary quinone electron acceptor of photosystem II } \\ \text { RISE } & \text { reduction-induced suppression of electron flow } \\ \text { ROS } & \text { reactive oxygen species } \\ \text { Y(II) } & \text { the quantum efficiency of photosystem II } \\ \text { Y(NO) } & \text { the quantum yield of non-regulated and non-photochemical energy dissipation at } \\ \text { Y(NPQ) } & \text { photosystem II } \\ \text { the quantum yield of non-photochemical quenching at photosystem II } \\ \text { Y(NA) } & \text { the quantum efficiency of photosystem I } \\ \text { Y(ND) } & \text { the quantum yield of the acceptor side limitation of photosystem I } \\ & \text { the quantum yield of the donor side limitation of photosystem I }\end{array}$

\section{References}

1. Lawlor, D.W.; Tezara, W. Causes of decreased photosynthetic rate and metabolic capacity in water-deficient leaf cells: A critical evaluation of mechanisms and integration of processes. Ann. Bot. 2009, 103, 561-579. [CrossRef]

2. Cruz de Carvalho, M.H. Drought stress and reactive oxygen species. Plant Signal. Behav. 2008, 3, 156-165. [CrossRef] [PubMed]

3. Xu, Z.; Zhou, G.; Shimizu, H. Plant responses to drought and rewatering. Plant Signal. Behav. 2010, 5, 649-654. [CrossRef] [PubMed]

4. Asada, K. The water-water cycle in chloroplasts: scavenging of active oxygens and dissipation of excess photons. Annu. Rev. Plant Mol. Biol. 1999, 50, 601-639. [CrossRef]

5. Müller, P.; Li, X.; Niyogi, K.K. Non-photochemical quenching. A response to excess light energy. Plant Physiol. 2001, 125, 1558-1566. [CrossRef] [PubMed]

6. Krieger-Liszkay, A. Singlet oxygen production in photosynthesis. J. Exp. Bot. 2005, 56, 337-346. [CrossRef]

7. Takagi, D.; Takumi, S.; Hashiguchi, M.; Sejima, T.; Miyake, C. Superoxide and singlet oxygen produced within the thylakoid membranes both cause photosystem I photoinhibition. Plant Physiol. 2016, 171, 1626-1634. [CrossRef]

8. Li, X.; Yang, Y.; Sun, X.; Lin, H.; Chen, J.; Ren, J.; Hu, X.; Yang, Y. Comparative physiological and proteomic analyses of poplar (Populus yunnanensis) plantlets exposed to high temperature and drought. PLoS ONE 2014, 16, e107605. [CrossRef]

9. Demmig-Adams, B.; Adams, W.W. III. Photoprotection and other responses of plants to high light stress. Annu. Rev. Plant Physiol. Plant Mol. Biol. 1992, 43, 599-626. [CrossRef]

10. Murata, N.; Takahashi, S.; Nishiyama, Y.; Allakhverdiev, S.I. Photoinhibition of photosystem II under environmental stress. Biochim. Biophys. Acta 2007, 1767, 414-421. [CrossRef]

11. Kudoh, H.; Sonoike, K. Irreversible damage to photosystem I by chilling in the light: cause of the degradation of chlorophyll after returning to normal growth temperature. Planta 2002, 215, 541-548. [CrossRef] [PubMed]

12. Sonoike, K. Photoinhibition of photosystem I. Physiol. Plant 2011, 142, 56-64. [CrossRef]

13. Sejima, T.; Takagi, D.; Fukayama, H.; Makino, A.; Miyake, C. Repetitive short-pulse light mainly inactivates photosystem I in sunflower leaves. Plant Cell Physiol. 2014, 55, 1184-1193. [CrossRef] [PubMed] 
14. Takagi, D.; Ishizaki, K.; Hanawa, H.; Mabuchi, T.; Shimakawa, G.; Yamamoto, H.; Miyake, C. Diversity of strategies for escaping reactive oxygen species production within photosystem I among land plants. Physiol. Plant 2017, 161, 56-74. [CrossRef]

15. Li, X.P.; Björkman, O.; Shih, C.; Grossman, A.R.; Rosenquist, M.; Jansson, S.; Niyogi, K.K. A pigment-binding protein essential for regulation of photosynthetic light harvesting. Nature 2000, 403, 391-395. [CrossRef] [PubMed]

16. Kramer, D.M.; Johnson, G.; Kiirats, O.; Edwards, G.E. New fluorescence parameters for the determination of $\mathrm{Q}_{\mathrm{A}}$ redox state and excitation energy fluxes. Photosynth. Res. 2004, 79, 209-218. [CrossRef] [PubMed]

17. Nilkens, M.; Kress, E.; Lambrev, P.; Miloslavina, Y.; Müller, M.; Holzwarth, A.R.; Jahns, P. Identification of a slowly inducible zeaxanthin-dependent component of non-photochemical quenching of chlorophyll fluorescence generated under steady-state conditions in Arabidopsis. Biochim Biophys Acta 2010, 1797, 466-475. [CrossRef] [PubMed]

18. Golding, A.J.; Johnson, G.N. Down-regulation of linear and activation of cyclic electron transport during drought. Planta 2003, 218, 107-114. [CrossRef] [PubMed]

19. Miyake, C.; Miyata, M.; Shinzaki, Y.; Tomizawa, K.I. $\mathrm{CO}_{2}$ response of cyclic electron flow around PSI (CEF-PSI) in tobacco leaves-relative electron fluxes through PSI and PSII determine the magnitude of non-photochemical quenching (NPQ) of Chl fluorescence. Plant Cell Physiol. 2005, 46, 629-637. [CrossRef] [PubMed]

20. Huang, W.; Yang, S.J.; Zhang, S.B.; Zhang, J.L.; Cao, K.F. Cyclic electron flow plays an important role in photoprotection for the resurrection plant Paraboea rufescens under drought stress. Planta 2012, 235, 819-828. [CrossRef] [PubMed]

21. Zivcak, M.; Brestic, M.; Balatova, Z.; Drevenakova, P.; Olsovska, K.; Kalaji, H.M.; Yang, X.; Allakhverdiev, S.I. Photosynthetic electron transport and specific photoprotective responses in wheat leaves under drought stress. Photosynth. Res. 2013, 117, 529-546. [CrossRef] [PubMed]

22. Zivcak, M.; Kalaji, H.M.; Shao, H.B.; Olsovska, K.; Brestic, M. Photosynthetic proton and electron transport in wheat leaves under prolonged moderate drought stress. J. Photochem. Photobiol. B 2014, 137, 107-115. [CrossRef] [PubMed]

23. Rott, M.; Martins, N.F.; Thiele, W.; Lein, W.; Bock, R.; Kramer, D.M.; Schöttler, M.A. ATP synthase repression in tobacco restricts photosynthetic electron transport, $\mathrm{CO}_{2}$ assimilation, and plant growth by overacidification of the thylakoid lumen. Plant Cell 2011, 23, 304-321. [CrossRef] [PubMed]

24. Tikhonov, A.N. pH-Dependent regulation of electron transport and ATP synthesis in chloroplasts. Photosynth. Res. 2013, 116, 511-534. [PubMed]

25. Shaku, K.; Shimakawa, G.; Hashiguchi, M.; Miyake, C. Reduction-induced suppression of electron flow (RISE) in the photosynthetic electron transport system of Synechococcus elongatus PCC 7942. Plant Cell Physiol. 2016, 57, 1443-1453. [PubMed]

26. Shimakawa, G.; Shaku, K.; Miyake, C. Reduction-induced suppression of electron flow (RISE) is relieved by non-ATP-consuming electron flow in Synechococcus elongatus PCC 7942. Front. Microbiol. 2018, 9, 886. [CrossRef]

27. Sejima, T.; Hanawa, H.; Shimakawa, G.; Takagi, D.; Suzuki, Y.; Fukayama, H.; Makino, A.; Miyake, C. Post-illumination transient $\mathrm{O}_{2}$-uptake is driven by photorespiration in tobacco leaves. Physiol. Plant 2016, 156, 227-238. [CrossRef]

28. Takagi, D.; Hashiguchi, M.; Sejima, T.; Makino, A.; Miyake, C. Photorespiration provides the chance of cyclic electron flow to operate for the redox-regulation of P700 in photosynthetic electron transport system of sunflower leaves. Photosynth. Res. 2016, 129, 279-290. [CrossRef]

29. Wada, S.; Suzuki, Y.; Takagi, D.; Miyake, C.; Makino, A. Effects of genetic manipulation of the activity of photorespiration on the redox state of photosystem I and its robustness against excess light stress under $\mathrm{CO}_{2}$-limited conditions in rice. Photosynth. Res. 2018, 137, 431-441. [CrossRef]

30. Shimakawa, G.; Murakami, A.; Niwa, K.; Matsuda, Y.; Wada, A.; Miyake, C. Comparative analysis of strategies to prepare electron sinks in aquatic photoautotrophs. Photosynth. Res. 2019, 139, 401-411. [CrossRef]

31. Allahverdiyeva, Y.; Mustila, H.; Ermakova, M.; Bersanini, L.; Richaud, P.; Ajlani, G.; Battchikova, N.; Cournac, L.; Aro, E.M. Flavodiiron proteins Flv1 and Flv3 enable cyanobacterial growth and photosynthesis under fluctuating light. Proc. Natl. Acad. Sci. USA 2012, 110, 4111-4116. [CrossRef] [PubMed] 
32. Yamamoto, H.; Takahashi, S.; Badger, M.R.; Shikanai, T. Artificial remodeling of alternative electron flow by flavodiiron proteins in Arabidopsis. Nat. plants 2016, 2, 16012. [CrossRef]

33. Gerotto, C.; Alboresi, A.; Meneghesso, A.; Jokel, M.; Suorsa, M.; Aro, E.M.; Morosinotto, T. Flavodiiron proteins act as safety valve for electrons in Physcomitrella patens. Proc. Natl. Acad. Sci. USA 2016, 113, 12322-12327. [CrossRef]

34. Zhou, Y.; Lam, H.M.; Zhang, J. Inhibition of photosynthesis and energy dissipation induced by water and high light stresses in rice. J. Exp. Bot. 2007, 58, 1207-1217. [CrossRef] [PubMed]

35. Kohzuma, K.; Cruz, J.A.; Akashi, K.; Hoshiyasu, S.; Munekage, Y.N.; Yokota, A.; Kramer, D.M. The long-term responses of the photosynthetic proton circuit to drought. Plant Cell Environ. 2009, 32, 209-219. [CrossRef] [PubMed]

36. Huang, W.; Fu, P.L.; Jiang, Y.J.; Zhang, J.L.; Zhang, S.B.; Hu, H.; Cao, K.F. Differences in the responses of photosystem I and photosystem II of three tree species Cleistanthus sumatranus, Celtis philippensis and Pistacia weinmannifolia exposed to a prolonged drought in a tropical limestone forest. Tree Physiol. 2013, 33, 211-220. [CrossRef] [PubMed]

37. Rollins, J.A.; Habte, E.; Templer, S.E.; Colby, T.; Schmidt, J.; von Korff, M. Leaf proteome alterations in the context of physiological and morphological responses to drought and heat stress in barley (Hordeum vulgare L.). J. Exp. Bot. 2013, 64, 3201-3212. [CrossRef] [PubMed]

38. Nankishore, A.; Farrell, A.D. The response of contrasting tomato genotypes to combined heat and drought stress. J. Plant Physiol. 2016, 202, 75-82. [CrossRef] [PubMed]

39. Zandalinas, S.I.; Rivero, R.M.; Martínez, V.; Gómez-Cadenas, A.; Arbona, V. Tolerance of citrus plants to the combination of high temperatures and drought is associated to the increase in transpiration modulated by a reduction in abscisic acid levels. BMC Plant Biol. 2016, 16, 105. [CrossRef]

40. Zhou, R.; Yu, X.; Ottosen, C.O.; Rosenqvist, E.; Zhao, L.; Wang, Y.; Yu, W.; Zhao, T.; Wu, Z. Drought stress had a predominant effect over heat stress on three tomato cultivars subjected to combined stress. BMC Plant Biol. 2017, 17, 24. [CrossRef] [PubMed]

41. Sehgal, A.; Sita, K.; Kumar, J.; Kumar, S.; Singh, S.; Siddique, K.H.M.; Nayyar, H. Effects of drought, heat and their interaction on the growth, yield and photosynthetic function of lentil (Lens culinaris Medikus) genotypes varying in heat and drought sensitivity. Front. Plant Sci. 2017, 8, 1776. [CrossRef] [PubMed]

42. Krishna Jagadish, S.V.; Muthurajan, R.; Rang, Z.W.; Malo, R.; Heuer, S.; Bennett, J.; Craufurd, P.Q. Spikelet proteomic response to combined water deficit and heat stress in rice (Oryza sativa cv. N22). Rice 2011, 4, 1-11. [CrossRef]

43. Rizhsky, L.; Liang, H.; Mittler, R. The combined effect of drought stress and heat shock on gene expression in tobacco. Plant Physiol. 2002, 130, 1143-1151. [CrossRef] [PubMed]

44. Wang, G.P.; Hui, Z.; Li, F.; Zhao, M.R.; Zhang, J.; Wang, W. Improvement of heat and drought photosynthetic tolerance in wheat by overaccumulation of glycinebetaine. Plant Biotech. Rep. 2010, 4, 213-222. [CrossRef]

45. Miyake, C.; Amako, K.; Shiraishi, N.; Sugimoto, T. Acclimation of tobacco leaves to high light intensity drives the plastoquinone oxidation system - relationship among the fraction of open PSII centers, non-photochemical quenching of Chl fluorescence and the maximum quantum yield of PSII in the dark. Plant Cell. Physiol. 2009, 50, 730-743. [CrossRef] [PubMed]

46. Hikosaka, K.; Kato, M.C.; Hirose, T. Photosynthetic rates and partitioning of absorbed light energy in photoinhibited leaves. Physiol. Plant 2004, 121, 699-708. [CrossRef]

47. Zivcak, M.; Brestic, M.; Kunderlikova, K.; Sytar, O.; Allakhverdiev, S.I. Repetitive light pulse-induced photoinhibition of photosystem I severely affects $\mathrm{CO}_{2}$ assimilation and photoprotection in wheat leaves. Photosynth. Res. 2015, 126, 449-463. [CrossRef]

48. Shimakawa, G.; Miyake, C. What quantity of photosystem I is optimum for safe photosynthesis? Plant Physiol. 2019, 179, 1479-1485. [CrossRef]

49. Takagi, D.; Amako, K.; Hashiguchi, M.; Fukaki, H.; Ishizaki, K.; Goh, T.; Fukao, Y.; Sano, R.; Kurata, T.; Demura, T.; Sawa, S.; Miyake, C. Chloroplastic ATP synthase builds up a proton motive force preventing production of reactive oxygen species in photosystem I. Plant J. 2017, 91, 306-324. [CrossRef]

50. Golding, A.J.; Finazzi, G.; Johnson, G.N. Reduction of the thylakoid electron transport chain by stromal reductants - evidence for activation of cyclic electron transport upon dark adaptation or under drought. Planta 2004, 220, 356-363. [CrossRef] 
51. Klughammer, C.; Schreiber, U. Deconvolution of ferredoxin, plastocyanin, and P700 transmittance changes in intact leaves with a new type of kinetic LED array spectrophotometer. Photosynth. Res. 2016, 128, 195-214. [CrossRef]

52. Schreiber, U.; Klughammer, C. Analysis of photosystem I donor and acceptor sides with a new type of online-deconvoluting kinetic LED-array spectrophotometer. Plant Cell Physiol. 2016, 57, 1454-1467. [CrossRef] [PubMed]

53. Takagi, D.; Miyake, C. PROTON GRADIENT REGULATION 5 supports linear electron flow to oxidize photosystem I. Physiol. Plant 2018, 164, 337-348. [CrossRef]

54. Wingler, A.; Quick, W.P.; Bungard, R.A.; Bailey, K.J.; Lea, P.J.; Leegood, R.C. The role of photorespiration during drought stress: an analysis utilizing barley mutants with reduced activities of photorespiratory enzymes. Plant Cell Environ. 1999, 22, 361-373. [CrossRef]

55. Cornic, G.; Fresneau, C. Photosynthetic carbon reduction and carbon oxidation cycles are the main electron sinks for photosystem II activity during a mild drought. Ann. Bot. 2002, 89, 887-894. [CrossRef]

56. Haupt-Herting, S.; Fock, H.P. Oxygen exchange in relation to carbon assimilation in water-stressed leaves during photosynthesis. Ann. Bot. 2002, 89, 851-859. [CrossRef] [PubMed]

57. Galmés, J.; Abadía, A.; Cifre, J.; Medrano, H.; Flexas, J. Photoprotection processes under water stress and recovery in Mediterranean plants with different growth forms and leaf habits. Physiol. Plant 2007, 130, 495-510. [CrossRef]

58. Chastain, D.R.; Snider, J.L.; Collins, G.D.; Perry, C.D.; Whitaker, J.; Byrd, S.A. Water deficit in field-grown Gossypium hirsutum primarily limits net photosynthesis by decreasing stomatal conductance, increasing photorespiration, and increasing the ratio of dark respiration to gross photosynthesis. J. Plant Physiol. 2014, 171, 1576-1585. [CrossRef]

59. Atkin, O.K.; Macherel, D. The crucial role of plant mitochondria in orchestrating drought tolerance. Ann. Bot. 2009, 103, 581-597. [CrossRef]

60. Petrov, V.; Hille, J.; Mueller-Roeber, B.; Gechev, T.S. ROS-mediated abiotic stress-induced programmed cell death in plants. Front. Plant Sci. 2015, 5, 69. [CrossRef]

61. Makino, A.; Mae, T.; Ohira, K. Differences between wheat and rice in the enzyme properties of ribulose-1,5-bisphosphate carboxylase/oxygenase and their relationship to photosynthetic gas exchange. Planta 1998, 174, 30-38. [CrossRef]

62. Baker, N.R. Chlorophyll fluorescence: a probe of photosynthesis in vivo. Annu. Rev. Plant Biol. 2008, 59, 89-113. [CrossRef]

63. Klughammer, C.; Schreiber, U. An improved method, using saturating light pulses, for the determination of photosystem I quantum yield via P700+-absorbance changes at $830 \mathrm{~nm}$. Planta 1994, 192, 261-268. [CrossRef]

64. Schreiber, U.; Klughammer, C. Saturation Pulse method for assessment of energy conversion in PS I. PAM App. Notes 2008, 1, 11-14.

65. Wada, S.; Hayashida, Y.; Izumi, M.; Kurusu, T.; Hanamata, S.; Kanno, K.; Kojima, S.; Yamaya, T.; Kuchitsu, K.; Makino, A.; Ishida, H. Autophagy supports biomass production and nitrogen use efficiency at the vegetative stage in rice. Plant Physiol. 2015, 168, 60-73. [CrossRef] [PubMed]

66. Yamaoka, C.; Suzuki, Y.; Makino, A. Differential expression of genes of the Calvin-Benson cycle and its related genes During leaf Development in rice. Plant Cell Physiol. 2016, 57, 115-124. [CrossRef]

67. Hidema, J.; Makino, A.; Mae, T.; Ojima, K. Photosynthetic characteristics of rice leaves aged under different irradiances from full expansion through senescence. Plant Physiol. 1991, 97, 1287-1293. [CrossRef]

68. Ihaka, R.; Gentleman, R. R: a language for data analysis and graphics. J. Comp. Graph. Stat. 1996, 5, $299-314$.

(C) 2019 by the authors. Licensee MDPI, Basel, Switzerland. This article is an open access article distributed under the terms and conditions of the Creative Commons Attribution (CC BY) license (http://creativecommons.org/licenses/by/4.0/). 